\title{
INMIGRANTES DE AMÉRICA CENTRAL Y DEL SUR EN ESPAÑA
}

\author{
José CORTIZO ÁLVAREZ \\ Departamento de Geografía y Geología -Universidad de León
}

Recibido: $15 / 03 / 2011$

Aceptado: 04/07/2010

RESUMEN: La inmigración de latinoamericanos en España (procedentes de países de América Central y del Sur) se ha incrementado considerablemente desde mediados de la década de 1990, con una tasa de crecimiento similar a la de los africanos y muy superior a la europea. Los empadronados de estas nacionalidades son casi 1,76 millones en el Padrón de 2008, algo más de un tercio de todos los extranjeros. Esta inmigración se caracteriza por su concentración en lo que se refiere a la procedencia, a los destinos y a las edades.

En primer lugar, en cuanto al origen, el 54\% de estos inmigrantes procede de tres países: Ecuador (24\%), Colombia (16\%) y Bolivia (14\%). En segundo lugar, en los destinos, casi la mitad de estos empadronados reside en las provincias de Madrid, Barcelona y Valencia; a la escala municipal, son también estos municipios y los de sus áreas metropolitanas los mayores receptores. Además de estas áreas, el litoral mediterráneo y las islas son también los destinos preferidos por estos inmigrantes. Finalmente, en lo que se refiere a la estructura por edades y sexo, la característica fundamental es, por un lado, la juventud, con la concentración de personas entre los 20 y los 44 años; por otro, el mayor peso proporcional de las mujeres.

PALABRAS CLAVE:Inmigración latinoamericana, concentración de procedencias, destinos y edades.

\section{IMMIGRANTS FROM CENTRAL AND SOUTH AMERICA IN SPAIN}

ABSTRACT: The immigration of Latin Americans to Spain (from Central and South America) has increased considerably since the mid 1990s, with rates of growth similar to those for Africans and much higher than those for Europeans. There are almost 1.76 million Latin Americans registered as residents in local municipalities, according to the Census of 2008 , accounting for over a third of all foreign residents. This immigration is characterized by its concentration in some countries of origin, destination and age.

Firstly, in terms of point of origin, 54\% of these immigrants come from three countries: Ecuador (24\%), Colombia (16\%) and Bolivia (14\%). Secondly, as regards destination, practically half of those registered live in the provinces of Madrid, Barcelona and Valencia. At municipal level, these same locations and their corresponding metropolitan areas are also the main recipients of immigration. In addition to these areas, the Mediterranean coast and the islands are also popular destinations for these immigrants. Finally, as regards age and sex, the fundamental pattern observed is on the one hand youth, with a high percentage of persons between 20 and 44 years of age, and on the other, a greater proportion of women.

KEY WORDS: Immigration of Latin Americans, concentration in: countries of origin, destination and age. 


\section{INTRODUCCIÓN. EVOLUCIÓN DE LA INMIGRACIÓN EN ESPAÑA (1991-2008)}

Los datos estadísticos que apoyan el texto que sigue están basados únicamente en la información ofrecida por los datos padronales del Instituto $\mathrm{Na}$ cional de Estadística (INEbase), tomando como objeto de estudio aquellas personas que en esta fuente aparecen agrupadas bajo el epígrafe de "nacionalidad extranjera" y procedentes de los países de América Central y de América del Sur.

Como se ha puesto de manifiesto en reiteradas ocasiones, en torno a esta inmigración existen dificultades de recuento, con el recurso a los datos censales o a las cifras ofrecidas por las administraciones con responsabilidad sobre las migraciones (GARCÍA BALLESTEROS, 2003: 69; DOMINGO, 2005; VALERO ESCANDELL, 2009: 15-16). Por nuestra parte, conscientes de las limitaciones que esto supone, hemos optado por la utilización de los datos padronales ofrecidos por el INE para ofrecer una foto fija con fecha de 1 de enero de 2008, tomando como objeto de estudio aquellas personas que en el citado Padrón figuran como extranjeros, clasificados por país de nacionalidad.

Desde una perspecgiva general, con frecuencia se señala el final del siglo XX como el momento de cambio del modelo migratorio en España, tras la larga etapa de transición que dejó atrás el periodo netamente emigratorio que caracterizó a España de 1946 a 1974 (LÓPEZ TRIGAL, 2006; FERRER y URDIALES, 2004).

Aunque la entrada de inmigrantes extranjeros no constituye un fenómeno nuevo, ya que se remonta a la década de 1960(LÓPEZ DE LERA, 1995), lo novedoso para nuestro país es el ritmo de incremento de los flujos de entrada, que se incrementa de manera notable en la década de 1990 y comienzos del siglo XXI, coincidiendo en este último caso con los procesos de regularización (IZQUIERDO, LÓPEZ y MARTÍNEZ, 2003).

La sustitución de los flujos emigratorios desde España ha tenido lugar desde la década de 1960, con la entrada de europeos que "de turistas, se transforman en residentes", corriente a la que se suman dos décadas después los latinoamericanos y, a finales de la década de 1980, los norteafricanos (PÉREZ DE LERA, 1995: 230).

El modelo actual está caracterizado por el fuerte impulso de la inmigración extranjera, en claro contraste con el resto de los países europeos tradicionalmente receptores de inmigración extranjera (Alemania, Francia), y por los cambios en la composición de ésta, particularmente en lo referido a las áreas 
de origen. En este modelo, la entrada masiva de inmigrantes ha elevado a más de 5 millones la cifra de empadronados extranjeros, según el Padrón de 2008, rebasando el 11\% de la población total en España.

En nuestro texto, en la evolución reciente de este fenómeno haremos referencia, en primer lugar, al incremento numérico de los inmigrantes extranjeros en España y, en segundo, al cambio de origen de estos inmigrantes.

En primer lugar, el cambio cuantitativo es muy importante, con el paso de poco más de 350.000 extranjeros empadronados en el Censo de 1991 a los casi 5,3 millones en el Padrón de 2008, según se recoge en la TABLA n ${ }^{\circ}$ 1; este salto supone que los inmigrantes, que eran el $0,91 \%$ de la población española en 1991, han pasado a ser el 11,41\% en la actualidad. En tasas, el incremento de efectivos significa un crecimiento del 1391,02\% entre ambas fechas o, lo que es lo mismo, que el número de extranjeros empadronados se ha multiplicado casi por 15 .

Tabla 1: Distribución de las grandes cifras de la inmigración, según continentes de origen, en 1991 y 2008

\begin{tabular}{lrrr}
\hline \multicolumn{4}{c}{$\mathbf{1 9 9 1}$} \\
\hline Procedencia & Inmigrantes & \% sobre tot. España & \% sobre tot. inmigr. \\
\hline Europa & 199367 & 0,51 & 56,42 \\
África & 42323 & 0,11 & 11,98 \\
América & 82066 & 0,21 & 23,22 \\
Asia & 22744 & 0,06 & 6,44 \\
Oceanía & 733 & 0,00 & 0,21 \\
Apátridas & 6134 & 0,02 & 1,74 \\
\hline ToTAL & 353367 & 0,91 & 100,00 \\
\hline \multicolumn{5}{c}{$\mathbf{2 0 0 8}$} \\
\hline Procedencia & Inmigrantes & $\%$ sobre tot. España & $\%$ sobre tot. inmigr. \\
\hline Europa & 2314425 & 5,01 & 43,93 \\
África & 909757 & 1,97 & 17,27 \\
América & 1784890 & 3,87 & 33,88 \\
Asia & 256728 & 0,56 & 4,87 \\
Oceanía & 2405 & 0,01 & 0,05 \\
Apátridas & 557 & 0,00 & 0,01 \\
\hline TOTAL & 5268762 & 11,41 & 100,00 \\
\hline FuENTE: INE. INEBASE, Censo de 1991 y Explotación del Padrón de 2008. Elaboración pro- \\
pia.
\end{tabular}


Gráfico 1. Tasa de incremento de los inmigrantes, según origen, entre 1991 y 2008 según las fuentes citadas ${ }^{*}$ )

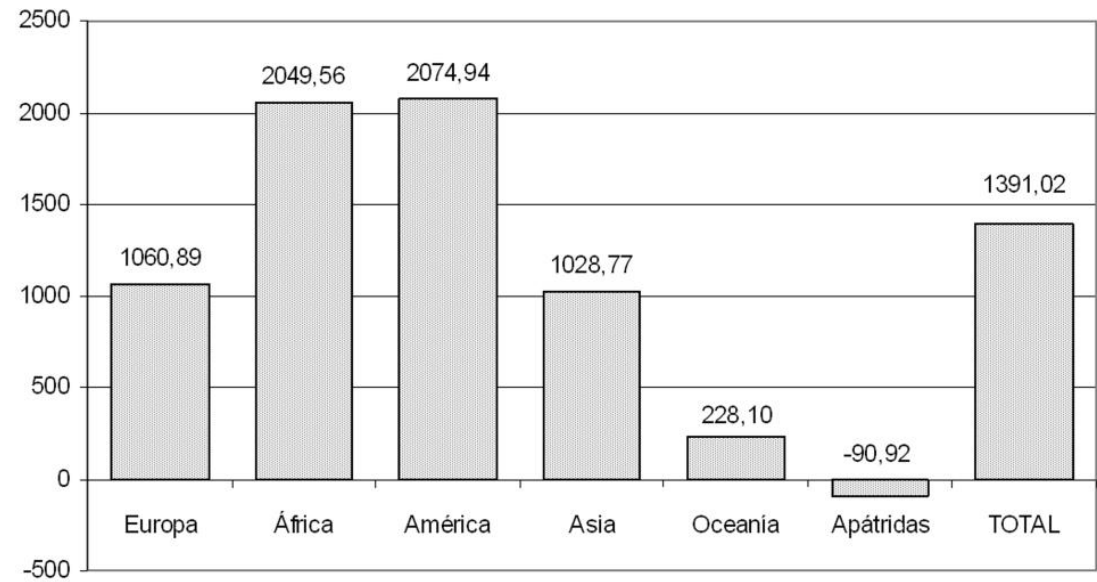

FuENTE: INE. INEBASE, Censo de 1991 y Explotación del Padrón de 2008. Elaboración propia. ${ }^{(*)}$ Tasa $=[(($ Inmigrantes 2008/Inmigrantes 1991)*100)-100]

En el segundo aspecto de esta evolución, lo más significativo es, por un lado, el paso de una inmigración mayoritariamente europea a la diversidad de orígenes y, por otro, la entrada creciente de la inmigración latinoamericana.

La inmigración de origen europeo sigue ocupando un puesto relevante, aunque ha perdido más de 12 puntos. Con respecto a este origen, el $91 \%$ de los empadronados corresponden a países de la Unión Europea, encabezados por los rumanos, que se han incorporado (junto con los búlgaros) a los orígenes tradicionales de Reino Unido, Alemania, Italia, Portugal y Francia.

En la inmigración africana, el colectivo marroquí sigue siendo mayoritario. Por su parte, por su parte, es destacable el aumento de la procedencia americana, con la ganancia de más de 10 puntos. En este sentido, distintos autores hablan de la "latinoamericanización" de los flujos inmigratorios, especialmente desde el final del siglo XX (IZQUIERDO, LÓPEZy MARTíNEZ, 2003; DOMINGO, 2005; MARTíNEZy GOLÍAS, 2005).

Con otra perspectiva, la tasa de incremento de los inmigrantes empadronados entre 1991 y 2008 que se representan en el GRÁFICO 1 es ilustrativa del cambio producido en los orígenes, puesto que África y América multiplican por más de 21 la cifra absoluta de empadronados de estas nacionalidades, mientras que los europeos lo hicieron "tan solo" por algo más de 11. 


\section{LA INMIGRACIÓN EXTRANJERA EN LA ACTUALIDAD. CONCENTRACIÓN EN CUANTO A LOS ORÍGENES: AMÉ- RICA CENTRAL Y DEL SUR}

La entrada creciente de inmigrantes señalada ha estado acompañada por la multiplicación de las nacionalidades de origen. En nuestro caso no vamos a entrar en consideraciones acerca de la incorporación de países de la Europa del Este en el flujo migratorio hacia España, ni de la fuerte corriente africana, nos centraremos en la inmigración procedente del continente americano.

Por lo que a América se refiere, los empadronados procedentes de este continente en 2008 son 1784 890, que aportan el 33,88\% de los inmigrantes en España y suponen el 3,87\% de la población española. En la composición de este flujo según procedencias destaca, como es previsible, la que tiene origen en los países del conjunto de América Central y del Sur, en los que incluimos a México y el Caribe; este colectivo alcanza la cifra de 1758295 personas, que supone un tercio de los extranjeros.

Como factores de atracción, en la base de la explicación de este flujo están los lazos de proximidad cultural, la generación de empleo que ha conocido nuestro país, las políticas de regularización, los acuerdos con algunos países de ese ámbito así como las mayores facilidades de la legislación española para que los latinoamericanos accedan a la nacionalización con respecto a otros inmigrantes (DOMINGO I VALLSy MARTínEZ, 2006: 103, 105; VICENTE TORRADO, 2005).

Por parte de estos países de América Central y del Sur, los factores de expulsión fueron, de manera genérica, tanto de orden político como económico. Recordemos que la década de 1980 fue la "década perdida" para la mayoría de estos países, a la que siguió una difícil década de crisis sociopolíticas, rematadas a comienzos del siglo XXI por las crisis puntuales de Ecuador, Argentina y Venezuela. En términos generales, pobreza, desigualdad, desempleo e inestabilidad política son caracteres comunes a la mayor parte de estos países y que explican en gran medida la emigración (GóMEZ QUINTERO, 2005).

A lo anterior se suma el endurecimiento de las condiciones de entrada en Estados Unidos tras los sucesos del 11-S. En este contexto, cerrados prácticamente los destinos internos y próximos en el continente americano, se explica el rápido crecimiento de la emigración hacia nuestro país (LÓPEZ DE LERA, PÉREZ CARAMÉS y VILLARES VARELA, 2004).

En esta inmigración americana, los países del Norte (Canadá y Estados Unidos) apenas si aportan efectivos (son 26 595, el 2,78\%); México está re- 
presentado por 23025 empadronados (1,29\%); América Central y el Caribe llegan al 9,65\% (172 230) y el grueso corresponde a los procedentes de los países de América del Sur, con el 87,57\% restante (1 463040 personas).

Mapa 1. Países de procedencia de la inmigración de América Central y del Sur (2008)

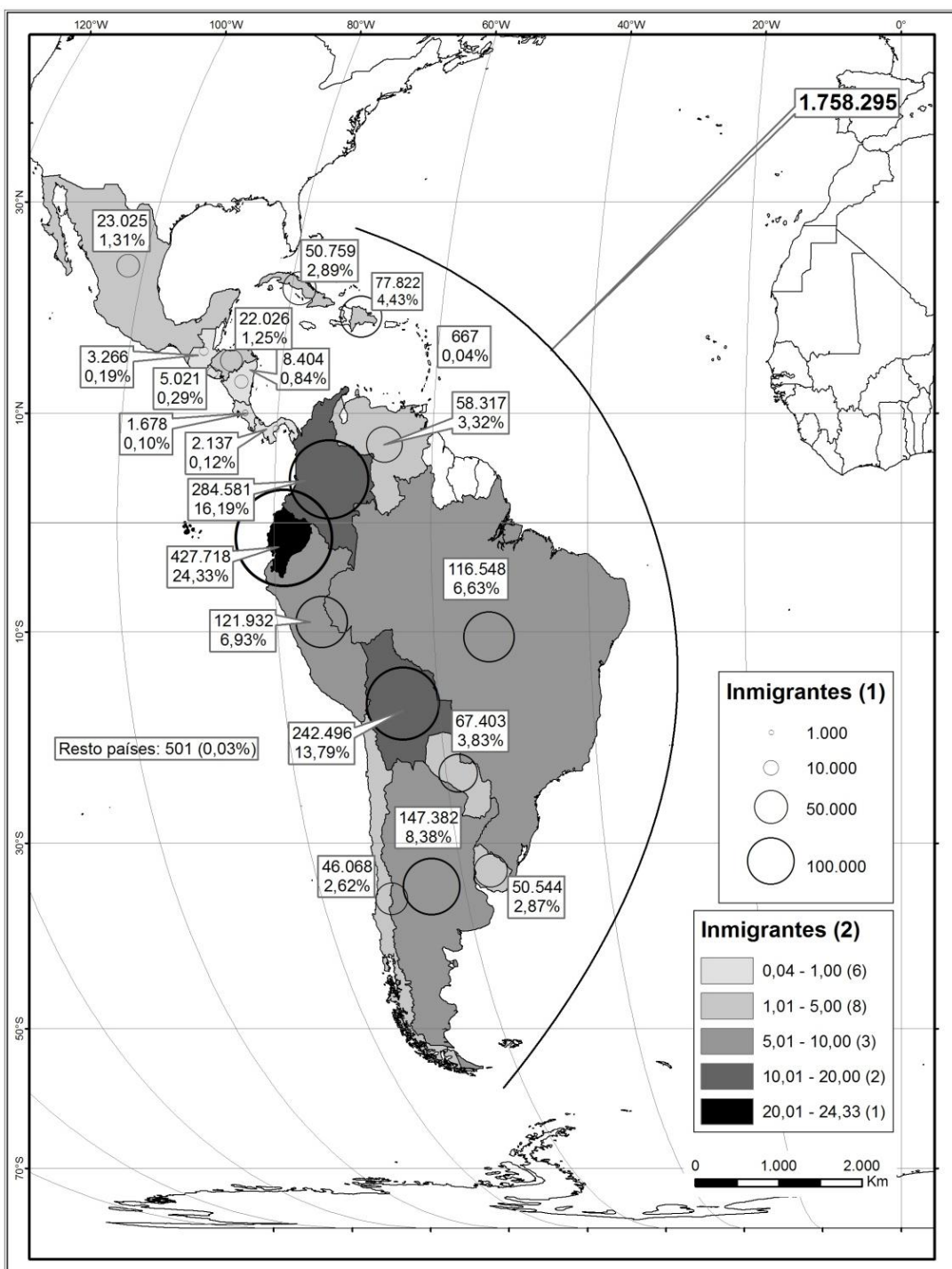

Fuente: InE. INEBASE, Censo de 1991 y Explotación del Padrón de 2008. Elaboración propia. (1): Inmigrantes latinoamericanos empadronados en España. (2): Porcentaje sobre el total de inmigrantes latinoamericanos 
Aumentando la escala a los países de origen de América Central y del Sur, estos son fundamentalmente Ecuador, Colombia y Bolivia, ya que entre los tres suman más del 54\% del total de estos inmigrantes. Si incluimos a $\mathrm{Ar}$ gentina, Brasil y Perú, estaríamos ante seis países que concentran más del $76 \%$ de los empadronados.

Tabla 2: Países de procedencia de la inmigración de América Central y del Sur (2008)

\begin{tabular}{lrr}
\hline Países & Inmigrantes & Porcentajes \\
\hline Ecuador & 427718 & 24,33 \\
Colombia & 284581 & 16,19 \\
Bolivia & 242496 & 13,79 \\
Argentina & 147382 & 8,38 \\
Perú & 121932 & 6,93 \\
Brasil & 116548 & 6,63 \\
Republica Dominicana & 77822 & 4,43 \\
Paraguay & 67403 & 3,83 \\
Venezuela & 58317 & 3,32 \\
Cuba & 50759 & 2,89 \\
Uruguay & 50544 & 2,87 \\
Chile & 46068 & 2,62 \\
México & 23025 & 1,31 \\
Honduras & 22026 & 1,25 \\
Nicaragua & 8404 & 0,48 \\
El Salvador & 5021 & 0,29 \\
Guatemala & 3266 & 0,19 \\
Panamá & 2137 & 0,12 \\
Costa Rica & 1678 & 0,10 \\
Dominica & 667 & 0,04 \\
Resto A. Central y Caribe & 450 & 0,03 \\
Resto América del Sur & 51 & 0,00 \\
\hline Total & 1758295 & 100,00 \\
\hline
\end{tabular}

FuENTE: INE. INEBASE, Censo de 1991 y Explotación del Padrón de 2008. Elaboración propia.

En las procedencias, como muy bien señalan Izquierdo, López y Martínez, se ha producido el relevo de las corrientes procedentes del Cono Sur por las del Área Andina IZQuIERDO, LÓPEZyMARTínEZ (2003). En estos países de procedencia, una serie de factores concretos han llevado a su población a emigrar a escala intrarregional (por ejemplo a Argentina, también en crisis), además de a España. Así, por ejemplo, en Ecuador ha sido determinante la dolarización de su economía en 1996 y su corolario de crisis (DoMINGO I VALLS y MARTíNEZ, 2006: 103); en Bolivia, por su parte, la juventud de su población y su estructura económica básicamente agrícola constituyen un excelente caldo de cultivo para la emigración. 
El alto número de ecuatorianos y colombianos empadronados en España puede estar relacionado, por otra parte, con los acuerdos entre España y estos países, en virtud de los cuales los nacionales de los mismos no necesitaban visado para entrar como turistas, hasta 1-01-2002 para Colombia y hasta 104-2003 para Ecuador (FERRER y URDIALES, 2004; DOMINGO I VALLS y MARTÍNEZ, 2006: 103).

En definitiva, los datos de procedencia que se recogen en la tabla y en el mapa que acompañan a este texto sustentan la idea de concentración del fenómeno de la inmigración en cuanto a los orígenes.

\section{LA CONCENTRACIÓN EN LOS DESTINOS}

En términos de distribución espacial de la inmigración extranjera en España, hay que señalar su alta concentración. De manera genérica, las áreas metropolitanas de Madrid y Barcelona, junto con el litoral mediterráneo y los territorios insulares se perfilan como los destinos preferentes; esta distribución reproduce la pauta general del conjunto de la población española (FERRER y URDIALES, 2004; BAYONA y DOMINGO, 2005).

De manera específica, para el caso de los nacionales de América Central y del Sur, los MAPAS 2 y 3 que acompañan este texto ilustran acerca de esa distribución espacial, que repite el modelo general. Las razones de esta concentración son de orden económico, puesto que las mencionadas áreas de acogida son también las de mayor densidad poblacional general, las de mayor dinamismo urbano y, en definitiva, las mayores generadoras de empleo industrial y terciario (sobre todo este último, en el que se ocupa la mayoría de estos inmigrantes).

En esta escala de los destinos, la concentración es notoria si tenemos en cuenta que tan solo tres provincias suman el $49,91 \%$ de los inmigrantes empadronados en España en 2008 procedentes de países de América Central y del Sur: Madrid (465 327, el 26,46\%); Barcelona (308 135, el 17,52\%), y Valencia (104 046, el 5,92\%).

Por otra parte, además de esta concentración, se aprecia la configuración de un eje secundario en el Mediterráneo que incluye Alicante, Murcia y Málaga y se prolonga hacia Sevilla, otro eje menor en el Valle del Ebro y el País Vasco y otro eje, discontinuo y de menor peso, en la cornisa cantábrica. En el interior, solamente destaca Toledo, por su proximidad a Madrid. Por su lado, los territorios insulares configuran otras dos áreas importantes de residencia de estos inmigrantes (FERRERy URDIALES, 2004). En el Anexo I se recogen las cifras desglosadas para todas las provincias españolas. 
Mapa 2. Distribución provincial de los inmigrantes de América Central y del Sur (2008)

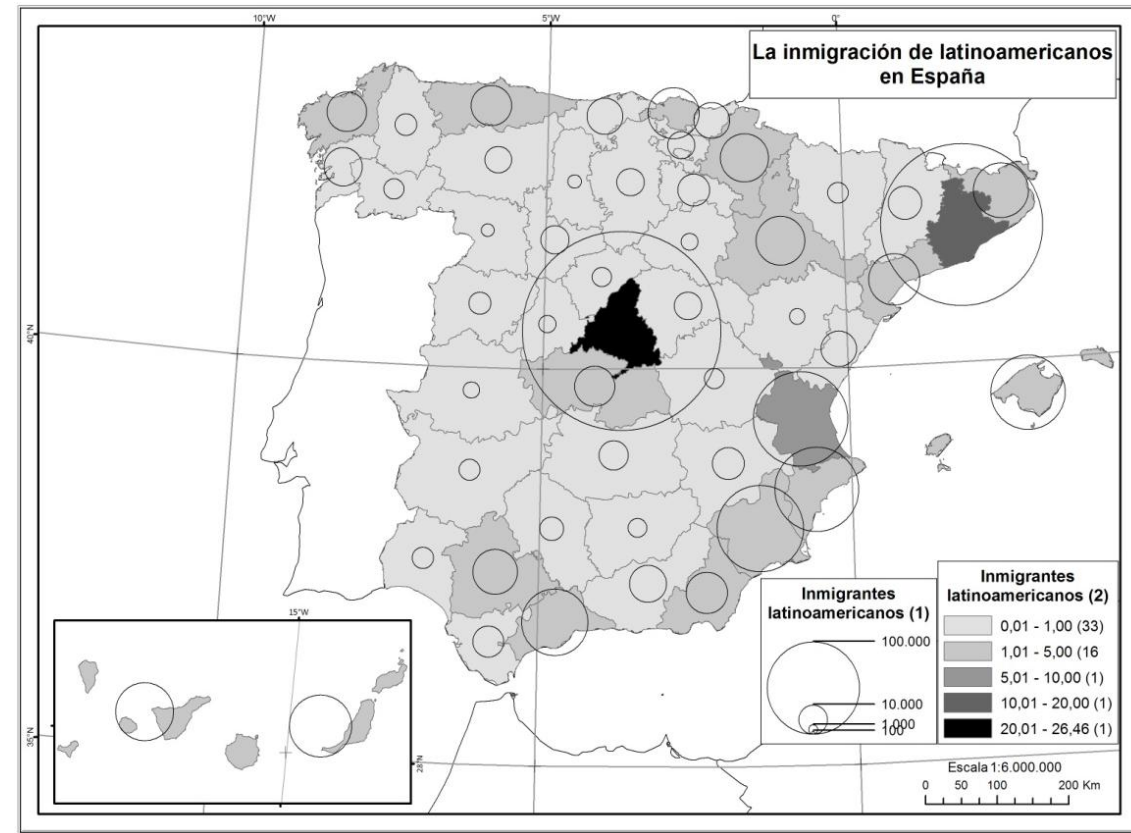

FuENTE: INE. INEBASE, Explotación del Padrón de 2008. Elaboración propia. (1): Inmigrantes latinoamericanos empadronados en España. (2): Porcentaje sobre el total de inmigrantes latinoamericanos.

Por nacionalidades de origen, la concentración es también clara; así, en la provincia de Madrid están más de la cuarta parte de los empadronados latinoamericanos pero, de hecho, el $45 \%$ de los peruanos reside en la misma; igualmente, más de la cuarta parte de los ciudadanos de la República Dominicana, Ecuador, El Salvador, Guatemala, México, Panamá y Paraguay están empadronados en Madrid. Por su lado, en la provincia de Barcelona están empadronados más del 25\% de los nacionales de El Salvador, Honduras, México y Chile y el 24\% de los peruanos. Finalmente, en la de Valencia residen también más de 100000 latinoamericanos, aunque el peso que tiene es significativamente menor que Madrid y Barcelona; en este caso, bolivianos, panameños, uruguayos, colombianos y ecuatorianos son, por este orden, los únicos que superan el 6\% sobre el total nacional.

Por otro lado, tomando como referencia el total nacional y la escala provincial, la composición según orígenes muestra la preponderancia de los empadronados de origen ecuatoriano, colombiano y boliviano, tanto en el conjunto de España como de las tres provincias citadas. 
Cambiando de escala, dentro de estas provincias, son los municipios de las capitales los que mayor peso tienen en el conjunto. A esta escala municipal, en el Padrón de 2008 encontramos 5582 municipios en los que hay empadronados inmigrantes de este origen aunque, de ellos, solamente 984 tienen más de 100 personas de estas nacionalidades. Por otra parte, en relación con el resto de las procedencias, en 3909 municipios son más numerosos los latinoamericanos que los africanos y en 1274 son más numerosos que los de origen europeo.

En esta escala nos hemos centrado en los municipios con más de 100 latinoamericanos y su distribución sigue la misma pauta espacial que hemos comentado para las provincias, marcada por la fuerte concentración en una pequeña porción del territorio nacional. Así, de manera más concreta, los 14 municipios españoles que tienen más de 10000 inmigrantes de estas nacionalidades acogen al 39\% de los inmigrantes latinoamericanos (TABLA 3 y MAPA 3). En gran medida coinciden con la configuración de las mencionadas áreas metropolitanas, el eje mediterráneo y los focos insulares.

Tabla 3: Distribución municipal de los inmigrantes de América Central y del Sur; municipios con más de 10000 inmigrantes (2008)

\begin{tabular}{lrrrr}
\hline \multicolumn{1}{c}{ Municipios } & $a$ & $b$ & $c$ & $d$ \\
\hline Madrid & 302399 & 17,20 & 56,04 & 9,41 \\
Barcelona & 112492 & 6,40 & 41,18 & 6,96 \\
Valencia & 55989 & 3,18 & 49,00 & 6,94 \\
Hospitalet de Llobregat & 35456 & 2,02 & 65,24 & 13,97 \\
Palma de Mallorca & 32438 & 1,84 & 41,95 & 8,18 \\
Murcia & 23227 & 1,32 & 41,35 & 5,39 \\
Zaragoza & 21065 & 1,20 & 26,56 & 3,16 \\
Alicante & 19661 & 1,12 & 41,03 & 5,93 \\
Málaga & 14654 & 0,83 & 36,19 & 2,59 \\
Bilbao & 14245 & 0,81 & 57,11 & 4,03 \\
Sevilla & 12795 & 0,73 & 42,72 & 1,83 \\
Las Palmas de Gran Canaria & 12586 & 0,72 & 42,34 & 3,30 \\
Pamplona & 11335 & 0,64 & 48,56 & 5,75 \\
Parla & 10273 & 0,58 & 38,34 & 9,51 \\
\hline SuMA & 678615 & 38,60 & 29,67 & 3,65 \\
\hline
\end{tabular}

$a$, Inmigrantes de América Latina; $b$, \% sobre total de inmigrantes latinoamericanos; $c$, \% sobre total de inmigrantes extranjeros; $d$, \% sobre población total municipal.

FuENTE:INE. INEBASE, Explotación del Padrón de 2008. Elaboración propia.

Por su parte, entre 5001 y 10000 empadronados latinoamericanos hay una serie de municipios que acaban de configurar las principales áreas receptoras de esta inmigración. Sin ánimo de ser exhaustivos hay que citar a Getafe, Móstoles, Alcobendas, Leganés, Fuenlabrada, Alcorcón, Torrejón de Hena- 
res, Majadahonda y Alcalá de Henares, en el área de Madrid, y a Badalona y Cornellá del Llobregat en Barcelona. A su vez, el mapa se completa, aunque con menor importancia numérica, con los municipios de Marbella, Granada, Elche, Lorca, Torrevieja, Cartagena, Gandía, Tarragona o Lérida, que constituyen un foco de concentración de carácter secundario que contribuye a reforzar este eje del Mediterráneo (BAYONAy GIL, 2008; POZOy GARCíA, 2009).

Mapa 3. Distribución municipal de los inmigrantes de América Central y del Sur; municipios con más de 100 inmigrantes (2008)

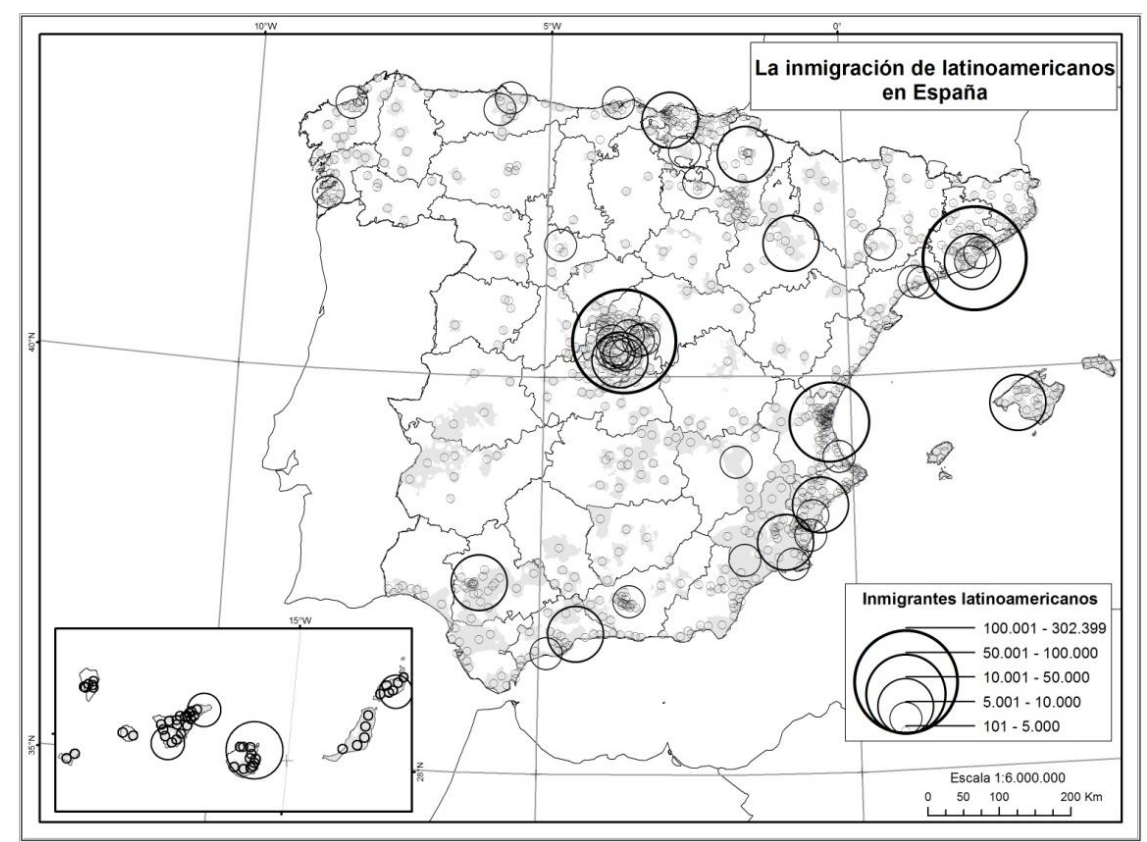

FuENTE: INE. INEBASE, Explotación del Padrón de 2008. Elaboración propia. Municipios con más de 100 inmigrantes empadronados.

Fuera de estos ámbitos metropolitanos y mediterráneos, algunos de los demás centros dinámicos del interior y de la cornisa cantábrica parecen perfilar otros destinos también secundarios para esta inmigración. En este segundo grupo, en la fachada norte y cantábrica están Vitoria, Santander, Oviedo y Gijón; en el interior, Logroño se integra en el mencionado eje del Ebro, mientras que Valladolid en la Meseta Norte y Albacete en la Sur aparecen como una especie de islas. De modo excéntrico en la península, La Coruña y Vigo ponen a Galicia en este mapa de la inmigración. Finalmente, los municipios canarios de Arona y Santa Cruz de Tenerife aportan la componente insular. 
Tanto la tabla anterior como el mapa nos indican que la concentración espacial en los destinos es también evidente en esta escala municipal. La concentración de los latinoamericanos está marcada por el predominio absoluto y proporcional de los municipios de Madrid, Barcelona y Valencia, en los cuales reside casi el $27 \%$ de todos los inmigrantes latinoamericanos empadronados en España.

Por lo demás, aparte de este hecho, debemos llamar la atención acerca de la relevancia de esta inmigración en otros municipios, tal como se recoge en la TABLA 3. Así, en primer lugar, si atendemos al porcentaje de empadronados latinoamericanos con respecto al número de extranjeros por municipios, vemos cómo en Hospitalet más del $65 \%$ de los inmigrantes son latinoamericanos, en Bilbao más del 57\% y en Madrid más del 56\%, mientras que Valencia y Pamplona están próximos al 50\%. En segundo lugar, considerando la proporción sobre la población municipal, también en Hospitalet cerca del $14 \%$ de su población total tiene esta procedencia, mientras que en Parla esa cifra llega al 9,51\%, en Madrid al 9,41\% y en Palma de Mallorca al 8,18\%; por su parte, otros cinco municipios capitales de provincia (Barcelona, Valencia, Murcia, Alicante y Pamplona) tienen porcentajes superiores al 5\%.

Estos valores relativos nos ayudan a matizar el significado de la inmigración latinoamericana más allá del simple número de empadronados, puesto que existen implicaciones de todo tipo (sociales, económicas, etc.) asociadas a la pura concentración numérica.

Las procedencias de estos inmigrantes en los municipios de Barcelona, Madrid y Valencia reproducen, en gran medida, la distribución provincial anterior.

\section{LA ESTRUCTURA POR EDADES Y SEXO DE LA POBLA- CIÓN LATINOAMERICANA EN ESPAÑA}

De los datos sintetizados en la TABLA 4 y en la pirámide de edades (GRÁFICO 3) se colige que, a grandes rasgos, la estructura de esta población empadronada de origen latinoamericano se caracteriza por su juventud, matizada por el predominio de los adultos-jóvenes, y en la cual hay una mayor proporción de mujeres.

La estructura está desequilibrada por el alto porcentaje de población entre 20 y 44 años (adultos-jóvenes), como corresponde a una inmigración hacia el trabajo, formada por adultos y familias jóvenes. De hecho, la población de estas cohortes supone el 64\% del total de empadronados latinoamericanos, mientras que los menores de 15 años son menos del $15 \%$ y los que tienen entre 45 y 65 años son tan sólo el 13\%. Los valores respectivos para el conjun- 
to de la población española son de 40, 14 y 13\% (IZQUIERDO, LÓPEZ y BUJÁN, 2003).

Tabla 4: Indicadores de estructura ${ }^{(1)}$ de la población (2008)

\begin{tabular}{lrr}
\hline & $\begin{array}{r}\text { Población total de } \\
\text { España }\end{array}$ & $\begin{array}{r}\text { Empadronados la- } \\
\text { tinoamericanos }\end{array}$ \\
\hline Tasa de vejez & $16,54 \%$ & $1,67 \%$ \\
Tasa de juventud & $14,42 \%$ & $14,57 \%$ \\
Índice de envejecimiento & $114,68 \%$ & $11,46 \%$ \\
Índice de longevidad & $27,82 \%$ & $14,14 \%$ \\
Edad media (en años) & 40,32 & 30,48 \\
Índice de renovación & $107,28 \%$ & $67,58 \%$ \\
Índice de dependencia & $44,84 \%$ & $19,38 \%$ \\
Índice de dependencia corregido & $29,60 \%$ & $10,29 \%$ \\
Índice de masculinidad general & $98,02 \%$ & $83,91 \%$ \\
Índice de masculinidad de 25-44 años & $106,39 \%$ & $83,19 \%$ \\
\hline (I) Valores calculados sobre los totales de los respectivos colectivos. En el Anexo II se inclu- \\
yen las fórmulas aplicadas. \\
\multicolumn{2}{|c}{}
\end{tabular}

Fuente: INE. INEBASE. Elaboración propia

El índice de masculinidad de esta población se ha reducido en los últimos diez años, pues si en 1997 había 54 hombres por cada 100 mujeres, en 2008 la proporción es de 84. La mujer latinoamericana fue pionera en esta inmigración pero el reagrupamiento familiar (hijos y esposo) ha ido equilibrando la relación entre los sexos (IZQUIERDO, LÓPEZy BUJÁN, 2003: 10-11; VICENTE TORRADO, 2005: 7-8). Por otro lado, recordemos que el índice de masculinidad para el total de España es de 114, de 115 para los empadronados procedentes del resto de la Unión Europea, de 164 para los asiáticos y de 194 para los africanos.

El desequilibrio entre sexos es muy marcado para determinadas nacionalidades. Así, las mujeres procedentes de algunos países superan ampliamente a los hombres en los casos de Nicaragua, Honduras, Paraguay, Dominica, Brasil o El Salvador. El resto de países también presenta estos desequilibrios, aunque menores; solamente se exceptúan Argentina, Chile, Perú y Uruguay, con cifras similares de hombres y mujeres.

Por otra parte, en relación con la gran proporción de población en esas cohortes de adultos-jóvenes, debemos destacar el hecho de que son edades clave tanto en lo económico como en el crecimiento natural de la población, puesto que están "en plena edad de trabajar, pero también en plena edad de procrear y/o crear una familia" (VICENTE TORRADO, 2005: 8). Es decir, a la potencialidad económica se añade la potencialidad procreativa, unida a su alta tasa de fecundidad (FERRERy URDIALES, 2004; LÓPEZ DE LERA, 2005); en 
Gráfico 2. Estructura de la población española y de los inmigrantes latinoamericanos (2008)

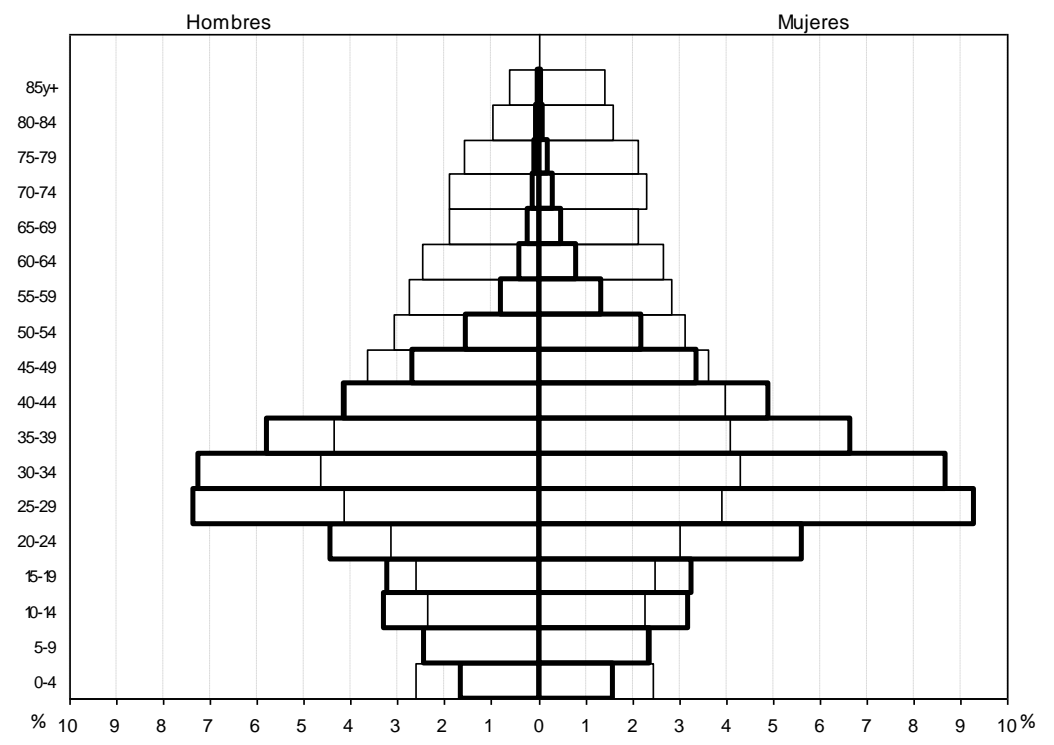

FUENTE: INE. INEBASE. Elaboración propia. Línea fina: población total española; línea gruesa: empadronados latinoamericanos

Gráfico 3. Pirámide de edades de los empadronados latinoamericanos (2008)

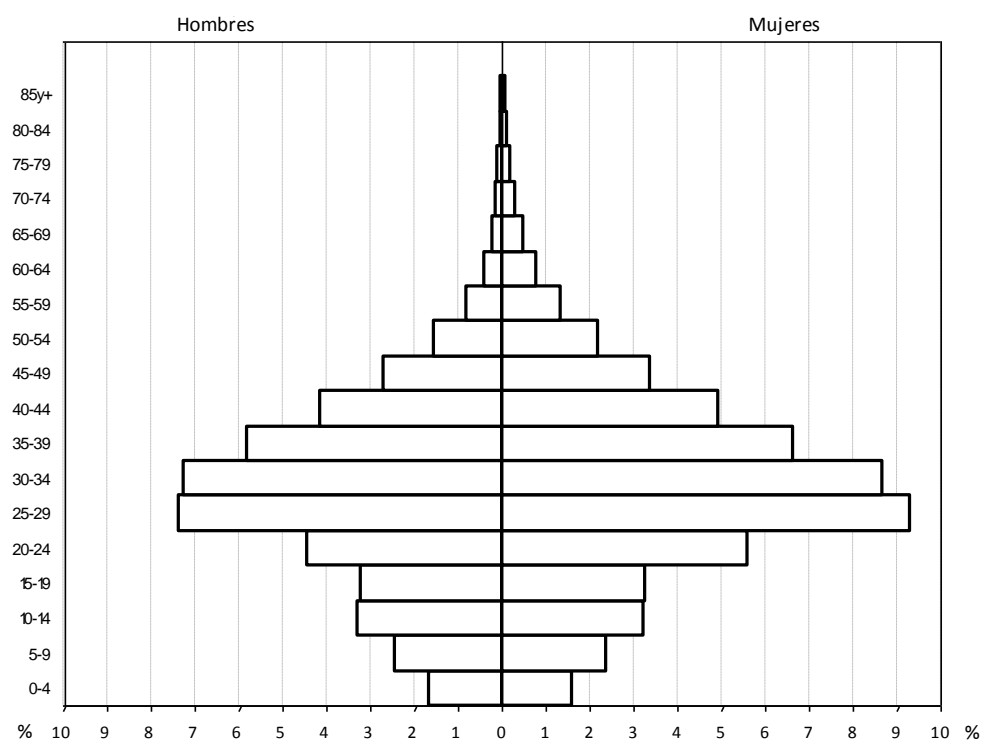

FUENTE: INE. INEBASE. Elaboración propia. 
Gráfico 4. Pirámide de edades de los empadronados latinoamericanos y los de la Unión Europea (2008)

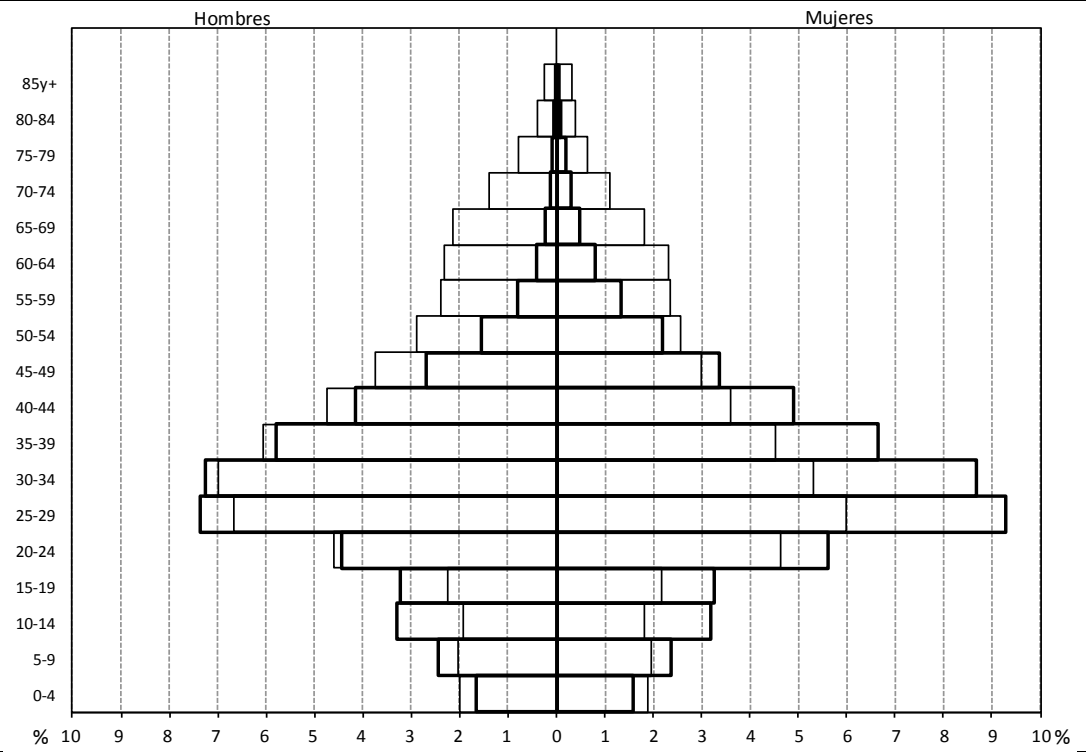

FUENTE: INE. INEBASE. Elaboración propia. Línea fina: empadronados procedentes de países de la UE; línea gruesa: empadronados latinoamericanos

Gráfico 5. Pirámide de edades de los empadronados latinoamericanos y de los africanos (2008)

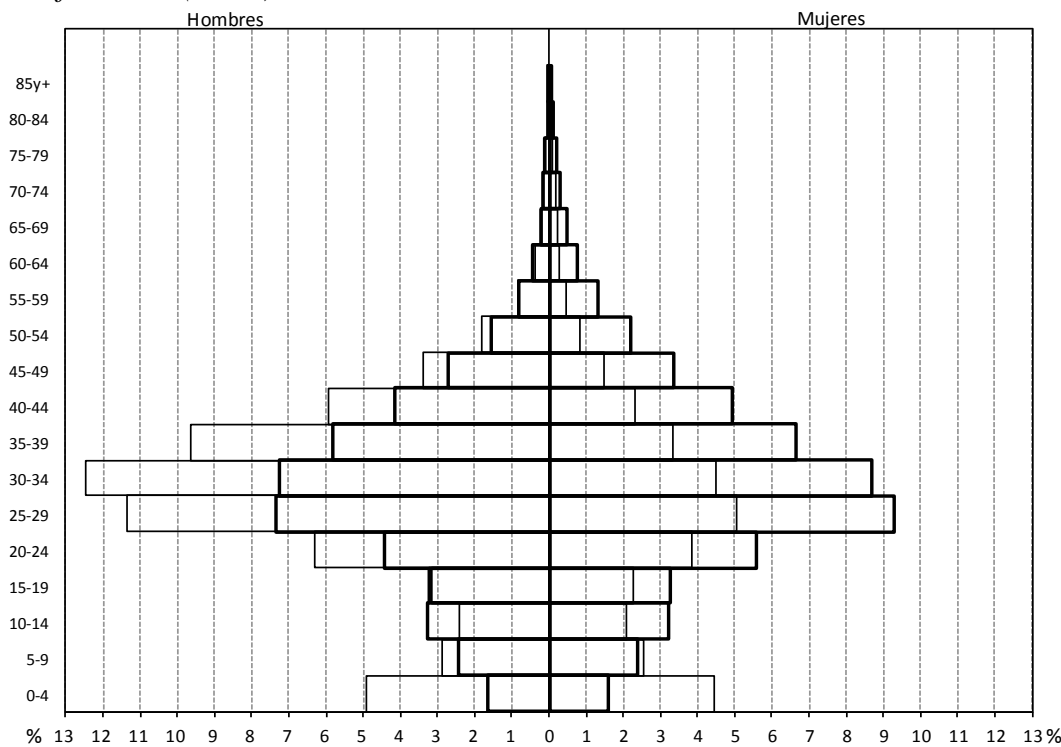

FUENTE: INE. INEBASE. Elaboración propia. Línea fina: empadronados de nacionalidades africanas; línea gruesa: empadronados latinoamericanos. 
este sentido, Diego López de Lera (2006) señala muy adecuadamente el aumento del número de extranjeras en las cohortes fértiles, en paralelo al descenso de las españolas. Por su lado, la base de la pirámide parece recoger tanto esta característica demográfica de alta fecundidad como el resultado del reagrupamiento familiar (DOMINGO, LEÓN y GARCÍA, 2009).

En la tabla anterior se ponen de manifiesto, de manera sintética, estos hechos:

$\checkmark$ la edad media de la población latinoamericana es diez años inferior a la del conjunto nacional

$\checkmark$ el índice de envejecimiento de la primera no es en absoluto relevante, mientras que el general muestra un claro envejecimiento

$\checkmark$ los ancianos latinoamericanos no llegan al $1,7 \%$ del total de inmigrantes, mientras que en la población española supera el $16 \%$

$\checkmark$ la proporción de adultos es del 69\% en el conjunto de España y del 83,5\% en estos inmigrantes

$\checkmark$ el predominio de las mujeres se refleja en los índices de masculinidad:

$\checkmark$ el de la población total es de $84 \%$ de hombres (98\% para el conjunto de la población española)

$\checkmark$ el de las cohortes de 25 a 44 años es de $83 \%$ (106\% para el total)

El perfil de estos inmigrantes contrasta con el de los procedentes de los países europeos, más próximo al de la población española ("los que vienen a descansar", en palabras de Diego López de Lera -1995-); sin embargo, la irrupción de los inmigrantes procedentes de la Europa del Este ha rejuvenecido en gran parte esta estructura europea (GRÁFICO 4). El contraste es también claro con los inmigrantes africanos, con una estructura marcadamente masculina, como corresponde a una entrada "exclusivamente por motivos laborales” (GÓMEZ FAYRÉN, 2003: 147) (GRÁFICO 5).

\section{CONCLUSIONES}

Los datos respecto al incremento del número de extranjeros empadronados en España, entre otras cuestiones, sustentan el cambio que ha llevado a la incorporación al acervo del lenguaje geodemográfico de expresiones del tenor de que España ha pasado de ser un país de emigración a serlo de inmigración. La cifra de esos más de 5 millones de extranjeros en España y la cifra de 1237832 españoles inscritos en el Censo electoral españoles residentes en el extranjero (CERA) apuntan en ese sentido (INE, a 1-01-09).

En nuestro breve análisis de la inmigración latinoamericana en España hemos tomando como fuente básica el Padrón Municipal, en su explotación de 2008 (con fecha de 1 de enero), asumiendo los problemas de recuento in- 
herentes al mismo. Las unidades de análisis para las procedencias son, en la escala más general, los grandes bloques que diferencia el Padrón, fundamentalmente América del Norte, América Central y Caribe y América del Sur y, de manera más concreta, se desciende a la escala de los países. En cuanto a los destinos, las escalas van desde la nacional hasta algunos ejemplos municipales.

Además del incremento numérico, la inmigración extranjera en España se caracteriza por la ampliación de los países de origen; así, aunque la procedencia sigue siendo mayoritariamente europea, los países africanos y, sobre todo, los del conjunto de América Central y del Sur, han multiplicado por más de 20 los efectivos empadronados en España en 2008 con respecto al Censo de 1991.

Esta procedencia está marcada por la concentración, de modo que, centrándonos en los países estudiados, Ecuador, Colombia y Bolivia aportan más del $54 \%$ de todos los inmigrantes latinoamericanos.

En los destinos en España, la concentración también es clara, puesto que el 49,91\% de los procedentes de países de América Latina y el Caribe reside en las provincias de Madrid, Barcelona y Valencia, por este orden de importancia.

A la escala municipal se repite la concentración en los municipios capitales de estas provincias y en los de su entorno, configurando una distribución que podemos definir básicamente como metropolitana, mediterránea e insular. Con menor importancia, se suman otros corredores en el valle del Ebro, en la cornisa cantábrica, en el occidente gallego y en las áreas insulares.

Por su parte, la estructura por edades y sexos nos muestra una población adulta-joven y perfil marcadamente femenino. No puede ser de otra manera cuando el $64 \%$ de esta población tiene entre 20 y 44 años y que entre 25 y 44 años hay 83 hombres por cada 10 mujeres.

Esta estructura se asocia a una inmigración hacia el trabajo y contrasta con la que muestran otras procedencias como la europea (similar a la española) o la africana (también adulta-joven pero masculina).

\section{BIBLIOGRAFÍA}

BAyona, J., Domingo, A. (2005): «Actividad y territorio: la localización de la población extranjera en Barcelona». Cuadernos de Geografía, n. ${ }^{\circ} 77$. Valencia, 1940, en línea, www.ub.es/geocrit/sn/sn-270-161.htm.

BAYONA, J., GIL, F. (2008): «El papel de la inmigración extranjera en la expansión de las áreas urbanas. El caso de Barcelona (1998-2007)». Scripta Nova. Revista 
Electrónica de Geografía y Ciencias Sociales, vol. XII, nº 270 (161). Barcelona, 1 de agosto de 2008.

Domingo, A. (2005): «Tras la retórica de la hispanidad: la inmigración latinoamericana en España, entre la complementariedad y la exclusión». Papers de Demografía, n. ${ }^{\circ}$ 254. Barcelona, Centre d'Estudis Demogràfics.

DOMINGO, A., MARTíneZ, R. (2006): «La población latinoamericana censada en España en 2001: un retrato sociodemográfico», Notas de Población, n. ${ }^{\circ}$. 81, 99127.

Domingo, A., LEÓN, P., GARCÍA, J. (2009): «El reagrupament familiar a la província de Barcelona, 2004-2006. Trets demogràfics i distribució territorial». Documents d'Anàlisi Geogràfica, n. ${ }^{\circ}$ 54. Girona, Universtitat de Girona, 55-78.

FERrER, A., URdiales, M. E. (2004): «Características de la población extranjera en España». Geo Crítica / Scripta Nova, Revista electrónica de Geografía y Ciencias Sociales, vol. VIII, n. ${ }^{\circ}$ 160, en línea, www.ub.es/geocrit/sn/sn-160.htm.

FAYRÉN, J. (2003): «Pluralidad sociodemográfica y cultural de la inmigración extranjera en España». Papeles de Geografía, n. ${ }^{\circ} 37,135-153$.

García BAllesteros, A. (2003): «Notas sobre la desigual distribución de los inmigrantes en España». Papeles de Geografía, n. $37,65-75$.

Guerra TAlAVERA, R., PÉREZ GARCíA, T. (2006): La inmigración latinoamericana en la provincia de Las Palmas en el cambio de siglo. Las Palmas de Gran Canaria, Cabildo de Gran Canaria.

QUINTERO, J. D. (2005): «La emigración latinoamericana: contexto global y asentamiento en España». Acciones e Investigaciones Sociales, n. ${ }^{\circ} 21,157-184$.

IZQuiERdo, A., LERA, D. L. de, MARTíneZ, R. (2003): «Los preferidos del siglo XXI: la inmigración latinoamericana en España», en CASTAÑO, F. J. GARCÍA, LÓPEZ, C. MURIEL (ed.) - La inmigración en España: contextos y alternativas (vol. II. Actas del III Congreso sobre la Inmigración en España). Granada, Laboratorio de Estudios Interculturales, 237-250.

LÓPEZ DE LERA, D. (1995): «Las inmigraciones en España a fines del siglo XX. Los que vienen a trabajar y los que vienen a descansar». Revista Española de Investigaciones Sociológicas, n. ${ }^{\circ}$ 71-72, 223-245.

LóPEZ DE LERA, D., PÉrez, A., Villares VArela, M. (2004): «Inmigración latinoamericana en Europa», en Encuentro Los latinos al descubrimiento de Europa. Nuevas emigraciones y espacios para la ciudadanía.Génova, Centro de Estudios Mediterráneos -Casa de América- Universidad de Génova. Edición en CD.

LÓPEZ DE LERA, D. (2005): «Características demográficas de los extranjeros en España», en XXV Conferencia Internacional de Población. Unión Internacional para el Estudio Científico de la Población. Tours (Francia). Edición en CD.

LÓPEZ DE LERA, D. (2006): «El impacto de la inmigración extranjera en las regiones españolas», en CORDón, Juan Antonio Fernandez, MALDONADO, Jesús Leal (coords.), Análisis territorial de la demografía española. Madrid, Fundación Fernando Abril Martorell, 233-272.

LÓPEZ TRIGAL, L. (2006): «La inmigración en España y Portugal. Cambio de modelo migratorio y efectos socioterritoriales», en La inmigración extranjera como 
desafío y esperanza. Alicante, Universidad de Alicante, Departamento de Geografía Humana, 139-155.

LÓPEZ TRIGAL, L. (2008): «La desigual distribución de la inmigración en España. Una exploración en las regiones interiores y atlánticas peninsulares», en GARCÍA RoCA, J., LACOMBA, J. (eds.) - La inmigración en la sociedad española. Una radiografía multicisciplinar. Barcelona, Ediciones Bellaterra, 139-155.

MARTíNEZ, R. (2003): «La reciente inmigración latinoamericana a España», en Serie Población y Desarrollo, n. ${ }^{\circ}$ 40, Comisión Económica para América Latina y el Caribe (CEPAL) Centro Latinoamericano y Caribeño de Demografía (CELADE). Santiago de Chile, $51 \mathrm{p}$.

MARTíneZ, R., GolíAS, M. (2005): «La latinoamericanización de la inmigración en España». Cuadernos Geográficos, n. ${ }^{\circ}$ 36, 51-64.

Pozo Rivera, E., García Palomares, J. C. (s/d): «Inmigración y cambio demográfico en la región metropolitana madrileña entre 1996 y 2006», en Anales de Geografía de la Universidad Complutense. Madrid: Universidad Complutense de Madrid, pp. 111-138.

VALERO ESCANDELL, J. R. (2009): «La España receptora: algunas transformaciones socioterritoriales en un período de inmigración intensa», en MONTORO, C., LÓPEZ, D., PONS, J. J., BARCENILlA, M ${ }^{\mathrm{a}}$ C. (eds.), La inmigración internacional: motor de cambios sociodemográficos y territoriales. Pamplona, Ediciones de la Universidad de Navarra, 15-36.

VICENTE TORRADO, T. L. (2005): «La inmigración latinoamericana en España». UN/POP/EGM-MIG/2005/12. United Nations Secretariat, México, 30-Nov.- 2 Dec. 2005. 


\section{ANEXO I: DISTRIBUCIÓN PROVINCIAL DE LOS INMI- GRANTES EXTRANJEROS. PADRÓN 2008}

\begin{tabular}{|c|c|c|c|c|c|c|c|c|c|}
\hline Provincias & $a$ & $b$ & $c$ & $d$ & $e$ & $f$ & $g$ & $h$ & $i$ \\
\hline Álava & 309635 & 0,67 & 22840 & 0,43 & 7,38 & 8956 & 39,21 & 2,89 & 0,51 \\
\hline Albacete & 397493 & 0,86 & 31128 & 0,59 & 7,83 & 11795 & 37,89 & 2,97 & 0,67 \\
\hline Alicante & 1891477 & 4,10 & 446368 & 8,47 & 23,60 & 83799 & 18,77 & 4,43 & 4,77 \\
\hline Almería & 667635 & 1,45 & 131330 & 2,49 & 19,67 & 19914 & 15,16 & 2,98 & 1,13 \\
\hline Asturias & 1080138 & 2,34 & 40804 & 0,77 & 3,78 & 19453 & 47,67 & 1,80 & 1,11 \\
\hline Ávila & 171815 & 0,37 & 11782 & 0,22 & 6,86 & 3528 & 29,94 & 2,05 & 0,20 \\
\hline Badajoz & 685246 & 1,48 & 21569 & 0,41 & 3,15 & 5260 & 24,39 & 0,77 & 0,30 \\
\hline Baleares & 1072844 & 2,32 & 223036 & 4,23 & 20,79 & 66095 & 29,63 & 6,16 & 3,76 \\
\hline Barcelona & 5416447 & 11,73 & 745216 & 14,14 & 13,76 & 308135 & 41,35 & 5,69 & 17,52 \\
\hline Burgos & 373672 & 0,81 & 32073 & 0,61 & 8,58 & 9083 & 28,32 & 2,43 & 0,52 \\
\hline Cáceres & 412498 & 0,89 & 13746 & 0,26 & 3,33 & 3083 & 22,43 & 0,75 & 0,18 \\
\hline Cádiz & 1220467 & 2,64 & 42804 & 0,81 & 3,51 & 11199 & 26,16 & 0,92 & 0,64 \\
\hline Cantabria & 582138 & 1,26 & 33242 & 0,63 & 5,71 & 15526 & 46,71 & 2,67 & 0,88 \\
\hline Castellón & 594915 & 1,29 & 106125 & 2,01 & 17,84 & 14612 & 13,77 & 2,46 & 0,83 \\
\hline Ciudad Real & 522343 & 1,13 & 41396 & 0,79 & 7,93 & 10520 & 25,41 & 2,01 & 0,60 \\
\hline Córdoba & 798822 & 1,73 & 21937 & 0,42 & 2,75 & 6763 & 30,83 & 0,85 & 0,38 \\
\hline La Coruña & 1139121 & 2,47 & 33711 & 0,64 & 2,96 & 18502 & 54,88 & 1,62 & 1,05 \\
\hline Cuenca & 215274 & 0,47 & 24348 & 0,46 & 11,31 & 4623 & 18,99 & 2,15 & 0,26 \\
\hline Gerona & 731864 & 1,59 & 149236 & 2,83 & 20,39 & 35277 & 23,64 & 4,82 & 2,01 \\
\hline Granada & 901220 & 1,95 & 58775 & 1,12 & 6,52 & 16103 & 27,40 & 1,79 & 0,92 \\
\hline Guadalajara & 237787 & 0,52 & 34310 & 0,65 & 14,43 & 8836 & 25,75 & 3,72 & 0,50 \\
\hline Guipúzcoa & 701056 & 1,52 & 35935 & 0,68 & 5,13 & 15117 & 42,07 & 2,16 & 0,86 \\
\hline Huelva & 507915 & 1,10 & 37110 & 0,70 & 7,31 & 5448 & 14,68 & 1,07 & 0,31 \\
\hline Huesca & 225271 & 0,49 & 24363 & 0,46 & 10,81 & 5021 & 20,61 & 2,23 & 0,29 \\
\hline Jaén & 667438 & 1,45 & 18572 & 0,35 & 2,78 & 4063 & 21,88 & 0,61 & 0,23 \\
\hline León & 500200 & 1,08 & 23380 & 0,44 & 4,67 & 8413 & 35,98 & 1,68 & 0,48 \\
\hline Lérida & 426872 & 0,92 & 69366 & 1,32 & 16,25 & 12770 & 18,41 & 2,99 & 0,73 \\
\hline Lugo & 355549 & 0,77 & 11582 & 0,22 & 3,26 & 5440 & 46,97 & 1,53 & 0,31 \\
\hline Madrid & 6271638 & 13,59 & 1005381 & 19,08 & 16,03 & 465327 & 46,28 & 7,42 & 26,46 \\
\hline Málaga & 1563261 & 3,39 & 250432 & 4,75 & 16,02 & 52513 & 20,97 & 3,36 & 2,99 \\
\hline Murcia & 1426109 & 3,09 & 225625 & 4,28 & 15,82 & 87522 & 38,79 & 6,14 & 4,98 \\
\hline Navarra & 620377 & 1,34 & 65045 & 1,23 & 10,48 & 27774 & 42,70 & 4,48 & 1,58 \\
\hline Orense & 336099 & 0,73 & 14006 & 0,27 & 4,17 & 4953 & 35,36 & 1,47 & 0,28 \\
\hline Palencia & 173454 & 0,38 & 5998 & 0,11 & 3,46 & 2168 & 36,15 & 1,25 & 0,12 \\
\hline Las Palmas & 1070032 & 2,32 & 142757 & 2,71 & 13,34 & 45694 & 32,01 & 4,27 & 2,60 \\
\hline Pontevedra & 953400 & 2,07 & 36269 & 0,69 & 3,80 & 17501 & 48,25 & 1,84 & 1,00 \\
\hline La Rioja & 317501 & 0,69 & 43856 & 0,83 & 13,81 & 11773 & 26,84 & 3,71 & 0,67 \\
\hline Salamanca & 353404 & 0,77 & 15355 & 0,29 & 4,34 & 5806 & 37,81 & 1,64 & 0,33 \\
\hline S. C. Tenerife & 1005936 & 2,18 & 141090 & 2,68 & 14,03 & 39593 & 28,06 & 3,94 & 2,25 \\
\hline Segovia & 163899 & 0,36 & 20451 & 0,39 & 12,48 & 4314 & 21,09 & 2,63 & 0,25 \\
\hline Sevilla & 1875462 & 4,06 & 62319 & 1,18 & 3,32 & 23545 & 37,78 & 1,26 & 1,34 \\
\hline Soria & 94646 & 0,21 & 8420 & 0,16 & 8,90 & 3578 & 42,49 & 3,78 & 0,20 \\
\hline Tarragona & 788895 & 1,71 & 139972 & 2,66 & 17,74 & 31325 & 22,38 & 3,97 & 1,78 \\
\hline Teruel & 146324 & 0,32 & 17043 & 0,32 & 11,65 & 3030 & 17,78 & 2,07 & 0,17 \\
\hline Toledo & 670203 & 1,45 & 74826 & 1,42 & 11,16 & 19273 & 25,76 & 2,88 & 1,10 \\
\hline Valencia & 2543209 & 5,51 & 294846 & 5,60 & 11,59 & 104046 & 35,29 & 4,09 & 5,92 \\
\hline Valladolid & 529019 & 1,15 & 29674 & 0,56 & 5,61 & 9453 & 31,86 & 1,79 & 0,54 \\
\hline Vizcaya & 1146421 & 2,48 & 58562 & 1,11 & 5,11 & 30792 & 52,58 & 2,69 & 1,75 \\
\hline Zamora & 197221 & 0,43 & 7669 & 0,15 & 3,89 & 1953 & 25,47 & 0,99 & 0,11 \\
\hline Zaragoza & 955323 & 2,07 & 113486 & 2,15 & 11,88 & 28810 & 25,39 & 3,02 & 1,64 \\
\hline Ceuta & 77389 & 0,17 & 3124 & 0,06 & 4,04 & 110 & 3,52 & 0,14 & 0,01 \\
\hline Melilla & 71448 & 0,15 & 6472 & 0,12 & 9,06 & 108 & 1,67 & 0,15 & 0,01 \\
\hline TOTAL & 46157822 & 100,00 & 5268762 & 100,00 & 11,41 & 1758295 & 33,37 & 3,81 & 100,00 \\
\hline
\end{tabular}

$a$, Población total; $b, \%$ sobre total; $c$, Poblaciónextranjera; $d$, \% sobre total de extranjeros;

$e$, \% extranjeros sobre población total; $f$. Inmigrantes de América Latina; $g$, \% sobre población extranjera; $h$, \% sobre población total; $i$, \% sobre total América Latina

INE. INEBASE. Elaboración propia. 


\section{ANEXO II: INDICADORES DE ESTRUCTURA DE LA PO- BLACIÓN}

\begin{tabular}{ll}
\hline Tasa de vejez o proporción de ancianos & $(\mathrm{P}>64 / \mathrm{PT}$ Total $) * 100$ \\
\hline Tasa de juventud o proporción de jóvenes & $(\mathrm{P}<15 / \mathrm{PT}$ Total $) * 100$ \\
\hline Índice de envejecimiento & $((\mathrm{P}>64) /(\mathrm{P} 15-64))^{*} 100$ \\
\hline Índice de longevidad o de sobreenvejecimiento & $(\mathrm{P}>79 / \mathrm{P}>64) * 100$ \\
\hline Edad media & $\begin{array}{l}\text { Calculada a partir de la población } \\
\text { de cada cohorte y su marca de } \\
\text { clase }\end{array}$ \\
\hline Índice de renovación o de tendencia & $(\mathrm{P} 0-4 / \mathrm{P} 5-9) * 100$ \\
\hline Índice de dependencia & $(\mathrm{P} 0-14+\mathrm{P} 65$ y más $) /(\mathrm{P} 15-64)$ \\
\hline Índice dependencia corregido (ponderado multiplicando & {$[((\mathrm{P} 0-14) * 0,5)+((\mathrm{P} 65$ y más $)$} \\
los jóvenes por 0,5 y los ancianos por 0,8) & $0,8) /(\mathrm{P} 15-64)]^{*} 100$ \\
\hline Índice de masculinidad & $(\mathrm{Pm} / \mathrm{Pf}) * 100$ \\
\hline Índice de masculinidad entre 25 y 44 años & $(\mathrm{Pm} 25-44 / \mathrm{Pf} 25-44) * 100$ \\
\hline
\end{tabular}

